\title{
Introduction
}

\section{Mobile/ubiquitous computing: dreams and nightmares}

\author{
Charles Ess, Johnny Soraker \& May Thorseth
}

Both the scholarly and certainly the popular literatures surrounding information and computing ethics make frequent reference to one or more revolutions. To be sure, in an age that has witnessed-and is increasingly driven by-rapid technological innovation and diffusion, it is tempting to believe that new technologies cannot help but to transform our lives and worlds in radical, dramatic, and thus revolutionary ways.

Insofar as the trope of revolution is justified-and, more importantly, whether the notion as applied to technological innovation is useful in the context of information and computing ethics - it seems fair to say that the last seventy years or so have witnessed at least three revolutions of interest to us here, beginning with the computing revolution of the 1930s onward. As is well known, "computers» were once the name for human beings who undertook arithmetic and mathematical calculations, aided only by printed reference tables, slide rules, and, by the early 20 th century, mechanical calculators. In simply quantitative terms, up until 1943 a human being with a slide rule could carry out a standard mathematical operation in $c .2$ seconds ( 0.5 operations per second or OPS). When the Marchant mechanical calculator was introduced at the Los Alamos labs in 1943 to assist with calculations required for the development of the atomic bomb, it doubled computation speed to 1 OPS. As electronic computers were introduced, the Los Alamos FERMIAC computer delivered 10 OPS by 1947. By 2010, the Los Alamos' supercomputers deliver over 100 trillion OPS. ${ }^{1}$ Expressed alternatively, the computational power of a 1970s' supercomputer is now vastly surpassed by a contemporary smartphone. ${ }^{2}$ 
The second revolutionary turn began in the early 1970s, when initial efforts were made to link computers, i.e., to allow electronic communication between them. By 1973, Vincent Cerf and Robert E. Kahn began developing what was later standardized as the Transmission Control Protocol/Internet Protocol (TCP/IP) that now connects millions of computers and over $26 \%$ of the world's population (cf. Abbate 2000: 127-133). Computer-mediated communication (CMC) became the subject of academic study at least by 1978 with Hiltz and Turoff's The Network Nation (1978: see Herring 2008: xxxv). As ARPANET and then NSFNET in the US gradually expanded and then opened up to commercial proprietary networks (e.g., CompuServe, Prodigy, etc.: Abbate 2000: 191-209) from the early 1990s onwards, our world has been transformed by the radical expansion of shared networked communication made possible by TCP/IP and what is now a generically shared Internet and World Wide Web (cf. Ess \& Consalvo, in press).

If these developments count as revolutionary, then a third revolution would appear to be underway: the sorts of computation, applications, and communication once the provenance of desktops and laptops are increasingly accessed via Internet-enabled smart phones. Such phones are now carried by the majority of populations in industrialized countries as a takenfor-granted, increasingly essential appliance. In the developing world, as dramatically less expensive and easier to service than a desktop or laptop, such phones are rapidly diffusing as the portal of choice for the Internet. At the same time, radio-frequency identification (RFID) tags and other technologies allow appliances as diverse as refrigerators and running shoes to transfer information via the Internet-developing an expanding web of «the internet of things».

Information and computing ethics struggle to address the specific ethical issues that these emerging technologies have evoked through the application of these new technologies, both through applying familiar ethical frameworks and as we are forced to grapple with challenges that seem to leap beyond the capacities of these frameworks. Especially, if indeed these technologies entail revolution, then it would seem that our ethical work will face very steep-perhaps insurmountable-challenges. That is, whatever else 'revolution' may imply, it would seem to suggest that much of previously established frameworks - including ethical frameworks-no longer give us the grip and facilities required to effectively think our way through radically new sorts of ethical dilemmas and issues.

For that, there is now a robust and extensive literature of information ethics regarding Information and Computing Technologies (ICTs) in the form of now «domesticated»- i.e., widely diffused and taken-for-granted appliances-networked laptops and desktops. By comparison, however, informed ethical reflection on mobile and ubiquitous computing is in its early stages. 
Hence, for this special issue we invited potential contributors to develop empirically-informed analyses and to present ethical reflections on the diverse ethical dimensions that arise in conjunction with mobile and ubiquitous computing technologies. We are very pleased with the quality and range of the contributions, both for the quality of their distinctive insights and reflections, and for what they collectively suggest regarding larger patterns in the ethics relating to these technologies, including - as we will see in our concluding remarks below-how far we are helped or hindered in our ethical work by the trope of revolution.

We begin with Rich Ling and Rhonda McEwen's «Mobile communication and ethics: implications of everyday actions on social order,» in part because Ling and McEwen introduce us to several crucial elements of mobile phone use, as well as to ethical frameworks that are commonly used to guide our reflections and judgments regarding their proper use.

Ling and McEwen highlight the peculiar tensions surrounding the mobile phone: it is highly individualized and personal-but as a communication device, the mobile provides both security and a sense of being tethered. These tensions thereby evoke distinctive social and ethical conflicts, specifically regarding the question: How do I respond to what may be an urgent SMS or phone call while in the middle of communicating and engaging with co-present friends, family, acquaintances, etc.?

As we would put it, the newness of this technology puts us in a kind of ethical twilight. On the one hand, generally shared norms and etiquette for mobile phone use are only gradually emerging, while on the other hand a phone call or message indication strikes with unexpected immediacy in a wide range of social situations, requiring snap judgments as to our proper action (i.e., whether to respond to or ignore the call or message). The good news is that we are increasingly able to make such judgments effectively. Using helpful traffic metaphors, Ling and McEwen observe that we often seek to «park» in some way our local engagements in order to determine whether or not to respond to a call or text. At the same time, however, they state that in many cases «the co-present interaction has a type of entrenched right of way when compared to talking on the phone.» Moreover, a central research finding is that mobile phones work to strengthen rather than fray our closest ties.

Litska Strikwerda's «Information privacy, the right to receive information and (mobile) ICTs» directly confronts the question of what information about individuals should be made public by the press and what information should remain private. Strikwerda approaches this question in terms of the tension between individual rights of privacy vis-à-vis the interests and right of the larger public to receive information. Drawing extensively on both legal definitions and philosophical discussion of privacy and information privacy, Strikwerda argues that we must balance individual 
rights to privacy vis-à-vis public interest through a principle of proportionality.

The problem, of course, is that ICTs - and especially mobile ICTs-challenge this proportionality or equilibrium, as they increase both our ability to generate and «publish» otherwise private information (e.g., physical location) and our ability to receive such information. Strikwerda argues that they nonetheless do not thereby change the balance needed between information privacy and the right to receive information as a member of the public: specifically she concludes: «We only have the right to receive information about others through the press if the information concerned is of public interest.» In short, for all their novelty, mobile ICTs do not appear to render extant law and ethics irrelevant; rather, these can continue to be used effectively to address the ethical challenges these new technologies bring in their wake.

Svein Sando's article «Play and virtuality» helps us explore important similarities and contrasts between play, as classically defined and discussed by Johan Huizinga, and virtual worlds. His central question is whether or not, as Huizinga claims, play is ethically neutral. For example, those who seek to defend the presence of explicit sex and violence in videogames from critics who worry about their potentially negative consequences sometimes resort to the claim «It's just a game»-meaning, in part, that the events depicted and played out in the game are ethically neutral. After reviewing and taking on board the analyses and arguments of several significant figures on play and virtuality, Sando uses the (in)famous example of a "rape in cyberspace» (Dibbell 1993) to argue that at least at points, play can, contra Huizinga, become evil. This claim is especially important insofar as mobile devices increasingly make ubiquitous in our lives the possibility of engaging in such computer-mediated play. In Sando's view, this ubiquity does not thereby somehow dilute the ethical dimensions or responsibility of our world-as it would if Huizinga were right. On the contrary, while these technologies may bring more opportunities for play into our everyday lives such play is not always ethically neutral, but rather requires ethical reflection and responsibility alongside our other everyday activities.

Anders Albrechtslund's «Deltagende overvågning og sociale fællesskaber på nettet» seeks to complement more prevailing notions of surveillance with his careful account of participatory surveillance. Albrechtslund reminds us of the more familiar-and far more negative-processes of surveillance at work in George Orwell's authoritarian «Big Brother» state, and in Bentham's conception of the panopticon, as made famous in the work of Foucault. By contrast, Albrechtslund highlights the multiple ways in which a kind of lateral and voluntary surveillance-«keeping an eye on one another»-is essential to human community and often experienced as a positive dimension of that community. Albrechtslund argues that this form 
of participatory surveillance helps us better understand the sorts of information sharing that we observe on social networking sites and other online communities. Specifically, what from an Orwellian or Foucauldian perspective would seem to be risky abandonment of privacy-e.g., various sorts of intimate thoughts and events now shared easily and frequently within at least small groups on a social networking site such as Facebook - can rather be understood as the sort of bid for and acceptance of intimacy and support that we seek and endorse in human communities familiar to us from offline experiences.

Elin Palm's «Informations och kommunikationstekniska lösningar i vård och omsorg för vem och varför?» turns our focus to another expression of ubiquitous and mobile computing, namely the use of ICTs and related technologies designed to provide specific kinds of care for the elderly. On the one hand, these technologies may help address the otherwise crushing problems of attempting to deliver quality health care to a rapidly growing elderly population in the developed countries. On the other hand, these technologies bring in their wake familiar ethical challenges. Palm focuses on three of these: personal integrity, freedom, and informed consent. Broadly, she argues that whatever the other pressures may be for introducing such technological solutions to meet pressing needs in healthcare, we can only do so by insuring that these basic ethical requirements and demands are recognized and protected.

Cornelius Cappelen's «Fair unemployment compensation and the target for egalitarian concerns,» along with Kristian Bjørkdahl's book review «Du er ikke en dings!» belong to the open section of this special issue, and as such they are not directly related to the remaining contributions. However, as we shall see, there are some interesting connections between Cappelen's paper and the core issues of this volume. To begin with, in discussing fair unemployment compensation, Cappelen brings to the fore an interesting discussion about the possible relevance of the difference between income losses and welfare losses when discussing compensation for the unemployed. A core question is in what respect people could be made more equal, and whether factors that we can be responsible for should be considered morally different from those that we cannot be held responsible for. By introducing some illuminating examples discussed by Dworkin and Cohen, the author undertakes a fine-grained analysis of this question. A second interesting connection that can be made with several of the other chapters-one that is specifically relevant to the discussion of ethical dimensions of new information technologies-is the question as to whether our lives are transformed in equalizing manners by way of access to and use of ICTs. Thereby, new technology can perhaps contribute to more equalization between citizens in the sense discussed by Cappelen, be they employed 
or unemployed. This question is not developed in this special issue, but would no doubt be an interesting research topic for another publication.

\section{Concluding remarks}

What is striking about the contributions taken together is that more often than not, moral frameworks and practices already in place seem largely sufficient to deal with the various ethical challenges that arise-including some of the most novel-in conjunction with new technologies. That is, we seem to be finding our moral footing with regard to mobile phone use (Ling and McEwen), how we deal with information online vis-à-vis print journalism and the public (Strikwerda), the ethics of play and virtual worlds (Sando), and ubiquitous computing in the domain of health care (Palm). Even Albrechtslund's account of participatory surveillance reminds us that what seem like distinctive new ways of apparently violating individual privacy in social networking sites and other online communities may be not so much revolutionary as they are a recovery and enhancement of ways of being together in human community that have operated since there have been such communities.

This is by no means to suggest that no revolution is at hand, or that further ethical challenges will be easily resolved without considerable, perhaps fatal, stress and strain on extant ethical frameworks. It is rather to suggest that as we approach the ethical dimensions of new technologies, we use the term 'revolution' with care, especially as it may misleadingly suggest that we are faced with ethical challenges that, as resting on what may indeed be considered genuinely revolutionary technologies and innovations, will thereby be beyond our grasp.

We may be helped here by the larger history of communication media. So, Asa Briggs and Peter Burke remind us with regard to the Print Revolution as first identified and documented by Elizabeth Eisenstein (drawing in turn on the work of Marshall McLuhan and Walter Ong). To be sure, the printing press and the diffusion of literacy indeed issued in profound social, political, and ethical change (including, we may note here, nothing less than the emergence of the modern democratic-liberal state and the sense of self as a moral autonomy that both requires and justifies such a state, cf. Ess 2010): but these changes required three centuries for their development and manifestation (i.e., from Gutenberg to Diderot's Encyclopédie). As with the Industrial Revolution, Briggs and Burke suggest we think of these transformations as a Long Revolution - though it remains a question as to «whether a revolution which is not rapid can be regarded as a revolution at all» (Briggs \& Burke 2002: 22). 
Whatever the possible applicability and ethical relevance of the label «revolution,» we are confident that the articles collected here will provide their readers with very helpful new insights and analyses, and add substantially to the still-nascent literature on the ethics of mobile computing and ubiquitous technologies. We wish to thank our contributors very much for their work and reflection, and to our readers-god fornøyelse!

\section{Notes}

1 See e.g., http://www.flickr.com/photos/8 399 025@N07/2 844162 097/

2 For example, a 1970s' mainframe might have had access to disk drives (the size of dishwashers) that could store $50 \mathrm{MB}$ of information, compared to the $2 \mathrm{~GB}$ or $4 \mathrm{~GB}$ routinely popped into a smartphone today. In terms of processing speed, measured in terms of floating point operations per second (flops), the first Cray-1 supercomputer operated at 150 megaflops (http://en.wikipedia.org/wiki/ History_of_computing_hardware_(1960s-present). A recently developed smartphone (developed in China) operates at 8 Gigaflops (http://www.mobilemarketingwatch.com/ouidoo-gaian-scene-augmented-reality-device-debuts-aims-to-createar-standard-6187/).

\section{Literature}

Abbate, J. (2000) Inventing the Internet. Cambridge, MA: MIT.

Briggs, A. \& Burke, P. (2002). A social history of the media: From Gutenberg to the Internet. Cambridge: Polity Press.

Ess, C. (2010) The embodied self in a digital age: Possibilities, risks, and prospects for a pluralistic (democratic/liberal) future? Nordicom Information 32 (2), pp. 105-118. Downloaded from http://www.nordicom.gu.se/common/publ_pdf/ 320_10\%20ess.pdf

Ess, C. \& Consalvo, M. (in press) What is «Internet studies» (Introduction). In The Blackwell handbook of Internet studies, eds. M. Consalvo \& C. Ess, pp. 1-8. Oxford: Wiley-Blackwell.

Herring, S. (2008). Foreword. In Handbook of Research on Computer Mediated Communication, eds. S. Kelsey \& K. St. Amant, vol. 1, pp. xxxv-xxxvi. Hershey, PA: Information Science Reference.

Hiltz, R. \& Turoff, M. (1978) The Network Nation. Reading, MA: AddisonWellesley. 


\section{Guest editors of Nordic Journal of Applied Ethics [Etikk i praksis] 2/2010}

Charles Ess is Professor MSO at the Department of Information and Media Studies, Aarhus University (2009-12). Recent publications include Digital Media Ethics (Polity Press, 2009) and, with Mia Consalvo (co-editor), The Blackwell Handbook of Internet Studies (2010). With Fay Sudweeks, he cofounded and co-chairs the biennial conference series «Cultural Attitudes towards Technology and Communication» (CATaC).

Johnny Hartz Søraker is Assistant Professor at the Department of Philosophy, University of Twente. His PhD dissertation dealt with the epistemology, ontology and ethics of virtual worlds, with a particular focus on their potential impact on personal well-being. His main interests lies in the intersections between computing and both theoretical and practical philosophy, often related to psychological research. He has published and lectured extensively on issues such as Internet governance, the psychological effects of technology, and the moral status of information.

May Thorseth is Professor at the Department of Philosophy, NTNU, Trondheim, Norway, director of Programme for Applied Ethics, and also part of the leader group of NTNU's Globalisation Programme. Most of her recent work has focussed on deliberative democracy, in particular related to online communication and virtual environments, and also on democracy and fundamentalism in view of global communication ethics. 